\title{
The Role of Emission Layer Morphology on the Enhanced Performance of Light-Emitting Diodes Based on Quantum Dot-Semiconducting Polymer Hybrids
}

\author{
Ana Fokina, Yeonkyung Lee, Jun Hyuk Chang, Myeongjin Park, Younghun Sung, \\ Wan Ki Bae,* Kookheon Char, Changhee Lee,* and Rudolf Zentel**
}

The influence of the morphology of quantum dot (QD)-semiconducting polymer hybrid emission layers on the performance of quantum dot-based light emitting diodes (QLEDs) is systematically investigated. Chemically grafted QD-semiconducting polymer hybrids are fabricated by the ligand exchange procedure between $\mathrm{CdSe} / \mathrm{Cd}_{x} \mathrm{Zn}_{1-x} \mathrm{~S}$ QDs and a new block copolymer consisting of a carbazole-based electroactive block with a low highest occupied molecular orbital level and a disulfide-based anchor block. The performance of QLEDs with hybrid emission layers is compared with QLEDs utilizing QD-only and physically mixed QD/polymer emission layers. It is shown that only in the emission layers formed by chemically grafted hybrids QDs are evenly distributed throughout the semiconducting polymer matrix. This leads to improved charge transport balance and suppressed photoluminescence quenching of QDs. As a result, hybrid QLEDs with the peak external quantum efficiency of $5.6 \%$ and the peak luminance of $21707 \mathrm{~cd} \mathrm{~m}^{-2}$ which outperform the conventional devices with QD-only emission layers are fabricated.

\section{Introduction}

Quantum dot (QD) based light-emitting diodes (QLEDs) are competitive alternatives to organic light-emitting diodes (OLEDs) in terms of color purity, luminescence intensities, and external quantum efficiencies (EQEs). ${ }^{[1-3]}$ Easily tunable emission wavelengths, narrow emission profiles, high photoluminescence quantum yields (PL QYs), and high stability of QDs are the basis for successful QLED performance. ${ }^{[4]}$ Multilateral efforts to understand the underlying device physics and to optimize the device structure have led to remarkable progress in the device performance and enabled to demonstrate high-efficiency QLEDs which can be comparable to OLEDs. ${ }^{[1,5-10]}$

The device performance is determined by the efficiency of QD emission layer under the device operation. The efficiency

Dr. A. Fokina, Prof. R. Zentel Institute for Organic Chemistry Johannes Gutenberg University

Duesbergweg 10-14, Mainz DE-55128, Germany

E-mail: zentel@uni-mainz.de

Dr. A. Fokina

Graduate School for Excellence Materials Science in Mainz

Johannes Gutenberg University Mainz

Staudingerweg 9, Mainz DE-55128, Germany

Y. Lee, Dr. M. Park, Prof. C. Lee

Department of Electrical Engineering and Computer Engineering

Inter-University Semiconductor Research Center (ISRC)

Seoul National University

1 Gwanak-ro, Gwanak-gu, Seoul 08826, Korea

E-mail: chlee7@snu.ac.kr

J. H. Chang, Dr. W. K. Bae

Photo-Electronic Hybrids Research Center

National Agenda Research Division

Korea Institute of Science and Technology

14-gil 5, Hwarang ro, Seongbuk gu, Seoul 02792, Korea

E-mail:wkbae@kist.re.kr

J. H. Chang, Y. Sung, Prof. K. Char

School of Chemical and Biological Engineering

The National Creative Research Initiative Center for Intelligent Hybrids

Seoul National University

1 Gwanak-ro, Gwanak-gu, Seoul 08826, Korea

DOI: 10.1002/admi.201600279 of QD emission layer can be understood on two different levels, the efficiency of individual QDs and the efficiency of QD ensembles, which are strongly affected by the structural/optical properties of QD emitters, the morphology of QD emissive layer, and the charge carrier (electron and hole) injection properties from charge transport layers into the QD emitters. The majority of previous approaches for high-efficiency QLEDs has leaned toward either the structural engineering of QD emitters or the optimization of charge transport layers..$^{[1,9-17]}$ Yet, despite its importance, efforts to control the morphology of QD emission layer have been largely lacking.

Herein, we investigate the role of the morphology of QD emission layer on the device performance. For systematic comparison, we prepare QD emission layers of different morphologies consisting of QD-only film, QD/semiconductor polymer blends, or QD-semiconducting polymer hybrids. The optoelectronic performance of QLEDs in correlation with the morphology of QD emission layers reveals that the hybridization of QDs with semiconducting polymers significantly enhances the emission efficiency of QD emitters by improving the charge carrier balance in QDs. In addition, the increase in the mean inter-dot distance in the hybrid QD emission layers effectively suppresses the energy transfer (ET) among QDs, leading to the enhancement of the efficiency of QD emission layer. Benefited 
from both, QLEDs with QD-semiconducting polymer hybrid emission layers display substantial enhancement in device efficiency (peak EQE of 5.6\%) and brightness (peak luminance of $21707 \mathrm{~cd} \mathrm{~m}^{-2}$ ) compared to the cases of QD-only $(2.0 \%$ and $16843 \mathrm{~cd} \mathrm{~m}^{-2}$ ) or physically blended QD/polymer emission layers $\left(1.7 \%\right.$ and $\left.4207 \mathrm{~cd} \mathrm{~m}^{-2}\right)$. We believe that the analysis and results in this article not only provide a practical guideline to control the morphology of QD emission layers for high-performance QLEDs, but also offer a useful platform for designing other optoelectronic devices utilizing QDs.

\section{Results and Discussion}

The difficulty in controlling the morphology of QD active layers without harming its optical or electrical properties has constrained the systematic study on the influence of the morphology of QD active layers on QLED performance. ${ }^{[18-21]}$ In this respect, QD-semiconducting polymer hybrids, in which charge carriers transport along conducting polymer brushes into QDs, provide an effective platform for the study. The strong affinity between the surface of QDs and the anchoring block of polymer brushes renders rather uniform distribution of QDs within semiconducting polymer matrices, so that one can control the morphology of hybrid emission layers (e.g., QD concentrations or mean inter-dot distances) by varying the mixing ratios between $\mathrm{QDs}$ and semiconducting polymers. ${ }^{[22,23]}$ In addition to that, the charge carrier transport through the semiconducting polymers can be adjusted through the choice of semiconducting polymers used, allowing us to increase the thicknesses of QD active layers or the mean QDto-QD distance within the emission layers without deteriorating the charge transport properties. ${ }^{[24,25]}$

$\mathrm{CdSe} / \mathrm{Cd}_{x} \mathrm{Zn}_{1-x} \mathrm{~S}$ core/shell Type-I heterostructured QDs with a core radius of $2.0 \mathrm{~nm}$ and a total radius of $4.5 \mathrm{~nm}$, which confine both hole and electron wave functions within the CdSe core (Figure 1a), are synthesized and utilized for the entire experiments. For qualitative comparison with the previous results, we chose this specific type of QDs that have extensively been used in our previous QLED and QD-semiconducting polymer hybrid studies. ${ }^{[25,26]}$

For the semiconducting polymer brushes, we used a new block copolymer (BP1) that contains an electroactive block bearing carbazole groups and an anchor block bearing disulfide groups (Figure 1b). Utilizing the reversible addition fragmentation chain transfer (RAFT) polymerization and post-polymerization modification techniques, the well-defined block copolymer with narrow molecular weight distribution was obtained (Figure S4, Supporting Information). The carbazole functionality was chosen as the electroactive unit due to
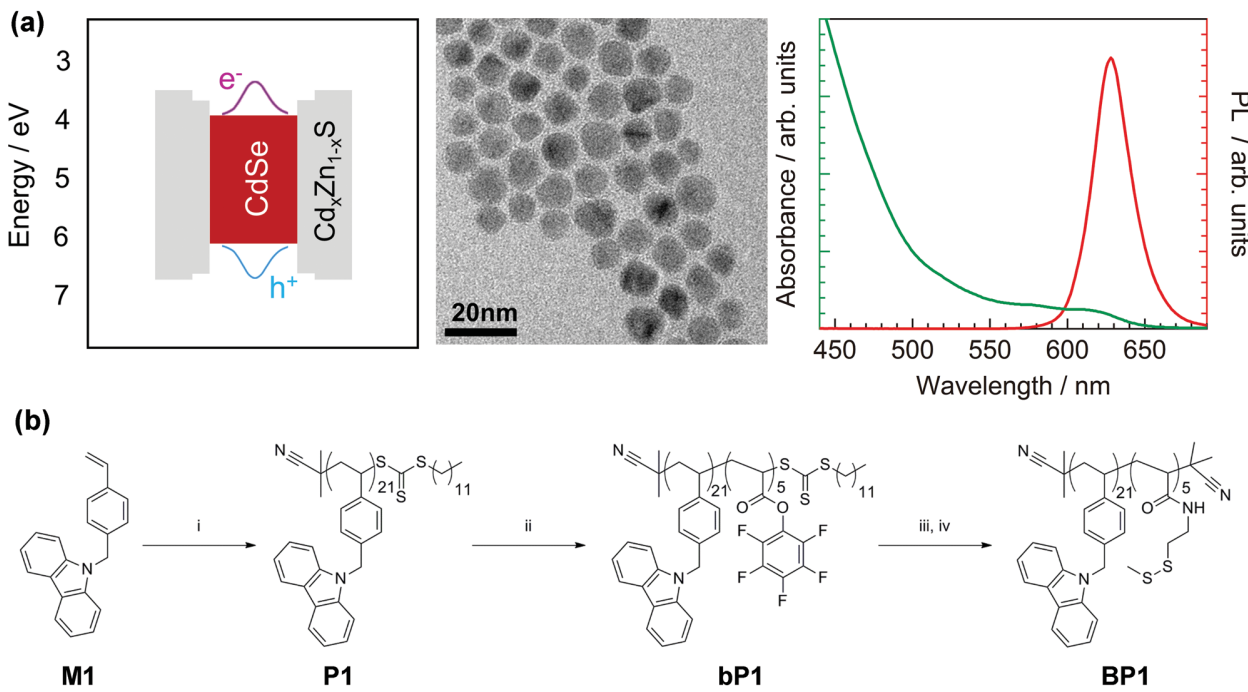

(c)
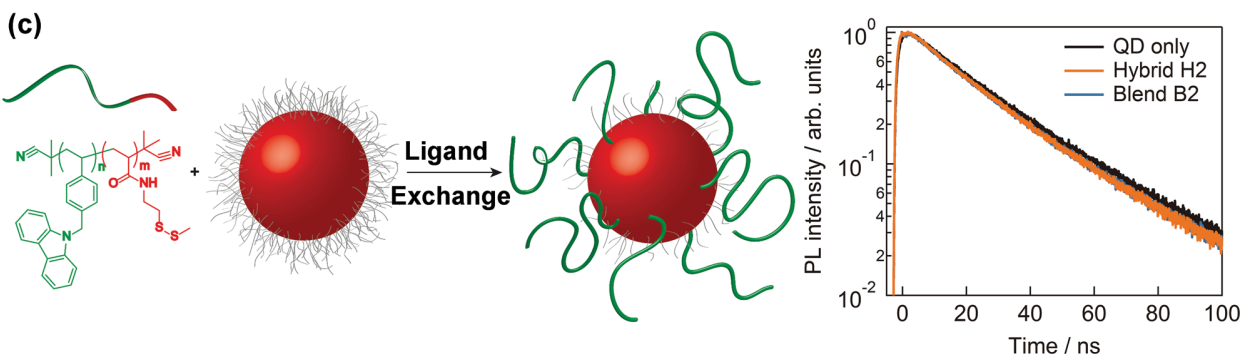

Figure 1. a) Schematic illustration of energy-band diagram (left), TEM image (middle), and absorption and PL spectra (right) of CdSe/Cd $Z \mathrm{Zn}_{1-x} \mathrm{~S}$ QDs. b) Scheme of block copolymer (BP1) synthesis; i: 2-cyano-2-propyl dodecyl trithiocarbonate, 2,2'-azobis (2-methylpropionitrile), THF, $65{ }^{\circ} \mathrm{C} 48$ h; ii: pentafluorophenyl acrylate, 2,2'-azobis (2-methylpropionitrile), THF, $65^{\circ} \mathrm{C} 69$ h; iii: 2,2'-azobis(2-methylpropionitrile), THF, $75{ }^{\circ} \mathrm{C} 24$ h; iv: 2 -methyldithio-ethylamine, triehtylamine, $\mathrm{THF}, 30^{\circ} \mathrm{C}, 24 \mathrm{~h}$. c) Schematic illustration of QD-polymer hybridization via the ligand exchange procedure (left) and solution PL-decay dynamics (right) of pristine QDs, QD/P1 blend (blend), and QD-BP1 hybrid (hybrid). 
its superior hole conducting properties and relatively low lying highest occupied molecular orbital (HOMO). ${ }^{[25]}$ Polystyrene backbone provides chemical and electrochemical robustness of the polymer brushes. The disulfide moieties of the anchor block possess the high affinity to unsaturated $\mathrm{Zn}$ centers, thus enabling the grafting of the polymer chains onto QD surfaces by replacing the pristine ligands (oleic acid).[27] The multiple anchor groups (in the anchor block) instead of only one anchor group facilitate the formation of stable polymer functionalized QDs. ${ }^{[28]}$

The QD-polymer hybrids $(\mathbf{H} 1-\mathrm{H} 3)$ were prepared by the ligand exchange procedure during which the oleic acid ligands initially coordinated to the QD surfaces were replaced with the BP1 polymer chains. The hybrids prepared in this study contain polymer functionalized QDs as well as different amounts of free polymers. By varying the QD and BP1 mixing ratios we prepared hybrid films with different morphologies (i.e., QD density per unit volume, mean QD-to-QD distance) (Table 1, Figure S9, Supporting Information). The increase in the polymer content in the hybrid films leads to the decrease in QD densities within the emission layers compared to the QDonly film. Additionally, to compare chemically grafted systems (QD-BP1 hybrids) to physically mixed counterparts we prepared blends of QDs with the semiconducting homopolymer P1' (QD/P1' blends, Figure S10, Supporting Information). Due to the absence of the anchor block in $\mathbf{P 1} \mathbf{1}^{\prime}$ (for the structure and synthesis of $\mathbf{P} 1^{\prime}$ see the Supporting Information), polymer chains in the QD/P1' blends are not attached to the QD surfaces, leading to the systems in which QDs and polymer chains are only physically mixed. We note that the optical properties of individual QDs, such as PL energy, PL decay dynamics, and PL QYs, remained unchanged throughout the ligand exchange hybridization procedure or the physical mixing with polymers (Figure 1c).

The main motivation of the present work is to investigate the relationship between the morphology of QD emission layers (QD-only vs QD/semiconducting polymer blend vs QDsemiconducting polymer hybrid) and the device performance. We focus on the comparison of these device characteristics to understand how the morphologies of the emission layers differ from each other and how they affect the device characteristics. For this purpose, hybrid (H2) and blend (B2) were chosen as

Table 1. Morphological characteristics of emission layers consisted of QD-BP1 hybrid ( $\mathrm{H} 1-\mathrm{H} 3)$, QD-only and QD/P1' blend (B2) films.

\begin{tabular}{lccc}
\hline Hybrid & $\begin{array}{c}\text { QD:polymer ratio } \\
{[\mathrm{wt} \%]}\end{array}$ & $\begin{array}{c}\text { Estimated QD density }{ }^{\mathrm{a})} \\
\text { [number of QDs cm }\end{array}$ & $\begin{array}{c}\text { Estimated mean QD- } \\
\text { to-QD distance } \\
{[\mathrm{nm} \text {, b) }}\end{array}$ \\
\hline $\mathrm{H} 1$ & $1: 0.5$ & $5.65 \times 10^{17}$ & 12.10 \\
$\mathrm{H} 2$ & $1: 0.375$ & $6.83 \times 10^{17}$ & 11.36 \\
$\mathrm{H} 3$ & $1: 0.25$ & $8.83 \times 10^{17}$ & 10.50 \\
QD only film & $1: 0$ & $9.63 \times 10^{17}$ & 10.10 \\
B2 & $1: 0.375$ & $6.83 \times 10^{17}$ & $\left.10.10^{c}\right)$ \\
\hline
\end{tabular}

a) Mathematically obtained considering QD and polymer densities; b) Core-tocore distance, $2 \mathrm{R}+$ (estimated polymer and ligand length); ${ }^{\mathrm{c}}$ Considering phase separation. the representative examples of hybrids and blends and compared with the conventional QD-only emission layer. Hybrid $\mathbf{H} 2$ and blend $\mathbf{B} 2$ possess the same QD- to-polymer mixing ratio of 1 to 0.375 .

We chose QLEDs with an inverted device architecture [ITO (150 nm)//ZnO nanoparticles $(40 \mathrm{~nm}) / /$ emission layer (QD-BP1 hybrids (H1-H3), QD-only film or QD/P1' blends) (30 nm)//4,4'-bis(9-carbazolyl)-1,1'-biphenyl (CBP) $(40 \mathrm{~nm}) / /$ MoOx (10 nm)//Al (100 nm)] (Figure 2a,b). In this setup, ZnO nanoparticles are responsible for the electron transport from a cathode (ITO) to the emission layer, whereas CBP and $\mathrm{MoO}_{x}$ layers are employed as the hole transport and hole injection layers, respectively. The device architectures for the hybrid, blend, and QD-only devices retained unchanged in order to isolate the effect of the morphology of QD emission layers on the device performances. In order to exclude the influence of electric field across the QD emission layers on the device characteristics, the emission layer thicknesses of hybrid and blend QLEDs were adjusted to be nearly constant in all the devices tested (Table 2). The emission layer thickness of $\approx 30 \mathrm{~nm}$ was chosen because QD-only QLED showed the best device performance with this film thickness with respect to the device efficiency, turn-on voltage, and roll-off behavior (Figure S11, Supporting Information).

Figure 2c-f shows the device characteristics (current $(J)$-voltage $(V)$, luminance $(L)$, external quantum efficiency, and electroluminescence (EL) spectra) of QLEDs with hybrid (H2), blend (B2), and QD-only emission layers. The devices with different emission layers exhibit the same shape of EL spectra, indicating that QDs are the dominant emitting centers in which injected electrons and holes recombine. In contrast, substantial differences are observed in the electrical properties and luminance of the devices. The hybrid QLED shows the peak EQE of 5.6\%, which is indeed over two times higher than that of QD-only (2.0\%) and blend (1.7\%) QLEDs. Besides, the maximum luminance of the hybrid device $(\mathbf{H} 2)$ is increased to 21707 from 16843 , and $4207 \mathrm{~cd} \mathrm{~m}^{-2}$ for the QD-only and blend (B2) devices, respectively.

Considering the decreased QD density in the hybrid emission layer due to polymer incorporation, the enhancement of the maximum luminance of the hybrid device compared to the QD-only device leads to the 2.5-fold increase in efficiency with respect to individual QDs. It should also be noted that all the hybrid devices tested (H1-H3, Figure 3) show higher EQE values and brighter luminance than the blend device with the same QD-to-polymer ratio (Figure S12, Supporting Information). Moreover, while the device with $\mathrm{H} 2$ shows the highest efficiency among the hybrid emission layers, all the hybrids H1-H3 regardless of QD-to-polymer ratios lead to QLEDs with improved device performance when compared with the conventional QLED with the QD-only emission layer, as shown in Figure 3. However, significant EQE roll-off behavior of the hybrid devices at applied voltages over $5 \mathrm{~V}$ is observed as polymer content increases. We hypothesize that the cause of this roll-off is a sudden change in the charge balance due to chemical degradation or morphological changes of the polymer. The ultimate cause of these changes may be external heating or excess charge carriers, although the exact mechanism is not understood at this point. 
(a)

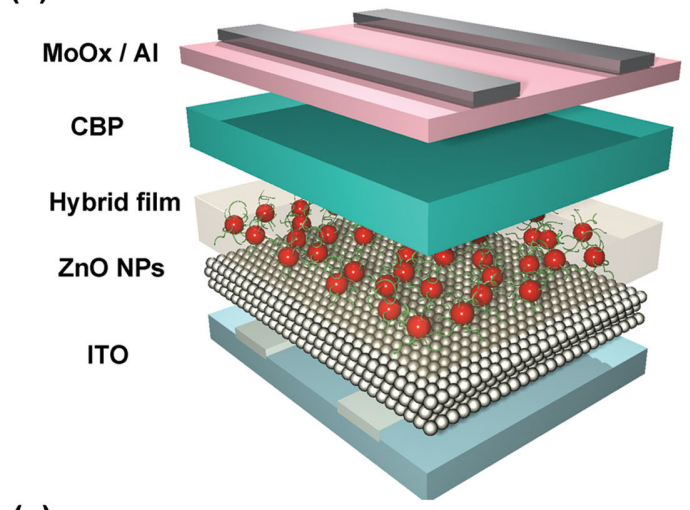

(c)

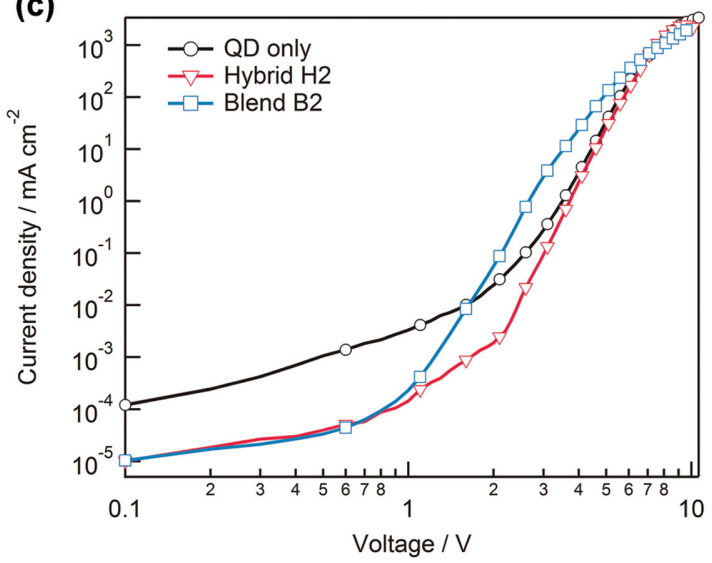

(e)

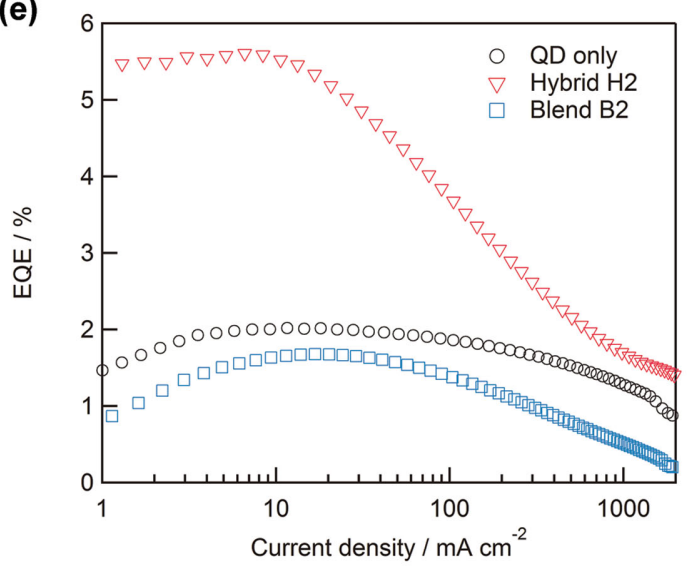

(b)

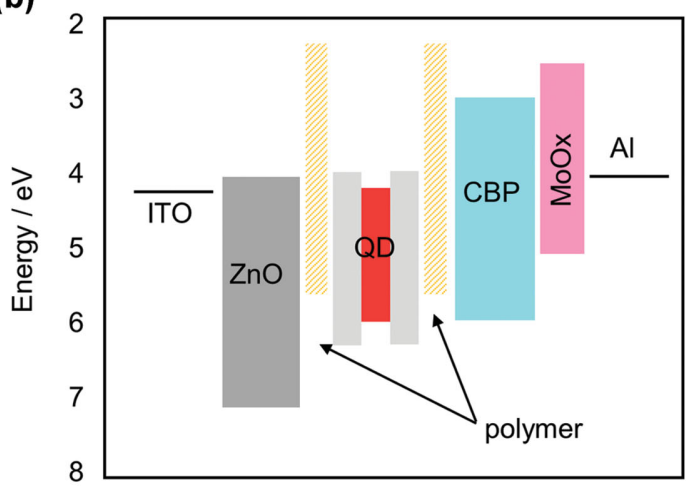

(d)

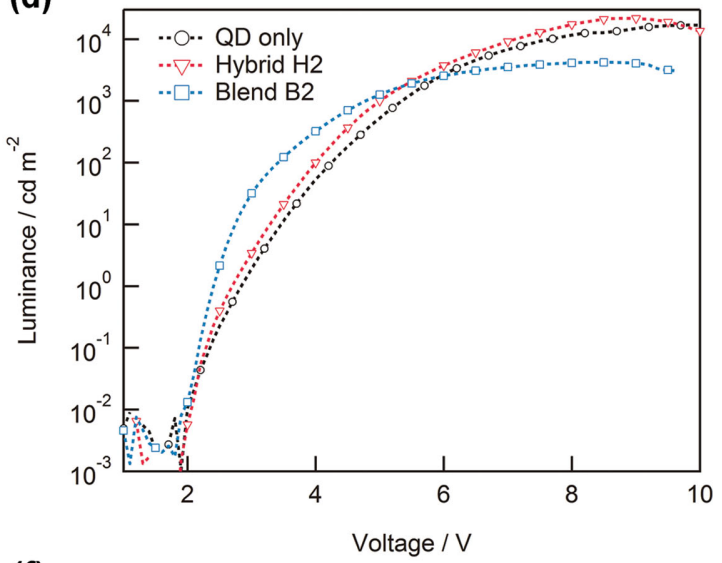

(f)

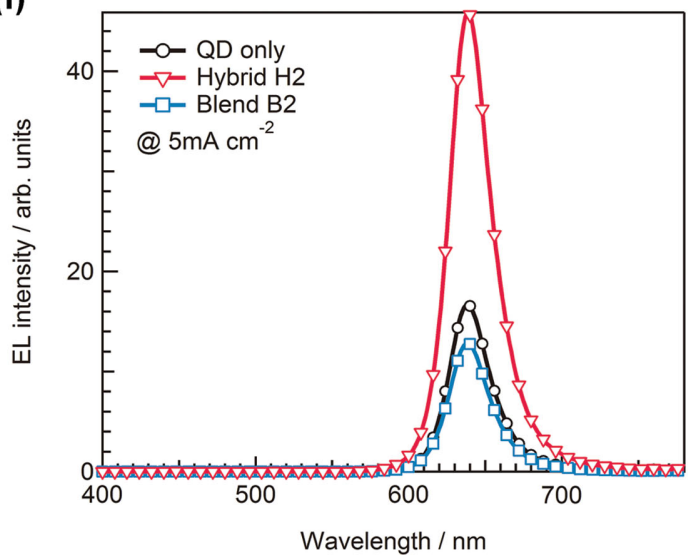

Figure 2. a) Schematic illustration and b) energy band diagram of hybrid QLEDs. Device characteristics of hybrid H2, blend B2, and QD-only QLEDs: c) current density versus voltage, d) luminance versus voltage, e) EQE versus current density, and f) EL spectra at $5 \mathrm{~mA} \mathrm{~cm}^{-2}$.

The enhanced hybrid device performance is attributed to the improved charge balance in the hybrid emission layer compared to the device with a QD-only emission layer. The hybrid devices show the reduced leakage current (i.e., current flow below the turn-on voltage) compared to the QD-only QLED by almost one order of magnitude (Figure 2c). The reduction in the leakage current is believed to be the direct consequence of the incorporation of semiconducting polymers between $\mathrm{ZnO}$ nanoparticles and QDs. In the chosen device structure, QDs in QD-only device are sandwiched between the CBP hole transport layer (HTL) and the electron transport layer (ETL) consisting of
$\mathrm{ZnO}$ nanoparticles (Figure 4b). Due to the relatively low conduction band edge and valence band edge energy levels of QDs compared to CBP, the electron injection rate from $\mathrm{ZnO}$ into QDs far surpasses the hole injection rate from CBP into QDs. The imbalance in charge injection results in the presence of excessive electrons in QDs that gives rise to the non-radiative exciton decays via Auger recombination process, subsequently leading to the reduction in the luminescence efficiency of QDs in operating QLEDs. ${ }^{[11,29]}$

In the hybrid devices, the carbazole-based BP1 polymer possesses relatively high lowest unoccupied molecular orbital 
Table 2. Device characteristics of QLEDs with emission layers consisting of QD-BP1 hybrid (H1-H3), QD-only and QD/P1' blend (B2) films.

\begin{tabular}{|c|c|c|c|c|c|c|}
\hline \multirow[t]{2}{*}{ Emission layer } & \multirow{2}{*}{$\begin{array}{c}\text { QD:polymer ratio } \\
\text { [wt\%] }\end{array}$} & \multirow{2}{*}{$\begin{array}{c}\text { Film thickness }{ }^{a)} \\
{[\mathrm{nm}]}\end{array}$} & \multirow{2}{*}{$\begin{array}{c}V_{\text {on }}[\mathrm{V}] \\
{\left[@ 1 \mathrm{~cd} \mathrm{~m}^{-2}\right]}\end{array}$} & \multirow{2}{*}{$\begin{array}{c}\text { Peak EQE } \\
{[\%]}\end{array}$} & \multicolumn{2}{|c|}{ @ $1000 \mathrm{~cd} \mathrm{~m}^{-2}$} \\
\hline & & & & & $V[V]$ & $J\left[\mathrm{~mA} \mathrm{~cm}^{-2}\right]$ \\
\hline $\mathrm{H} 1$ & $1: 0.5$ & 33 & 3.1 & 3.3 & 6.0 & 30.27 \\
\hline $\mathrm{H} 2$ & $1: 0.375$ & 32 & 2.7 & 5.6 & 5.0 & 25.51 \\
\hline $\mathrm{H} 3$ & $1: 0.25$ & 31 & 2.4 & 4.3 & 4.7 & 43.44 \\
\hline QD only & $1: 0$ & 33 & 2.9 & 2.0 & 5.4 & 74.13 \\
\hline B2 & $1: 0.375$ & 34 & 2.4 & 1.7 & 4.8 & 90.21 \\
\hline
\end{tabular}

a) Film thicknesses determined by ellipsometry and STEM.

(LUMO) energy level of $2.32 \mathrm{eV}$ and thereby effectively suppresses the excess electron injection from $\mathrm{ZnO}$ compared to the QD-only QLED (Figure 4a). ${ }^{25]}$ The current density values of QLEDs with H1-H3 hybrid emission layers, at the same applied voltage, decrease gradually with the increase in polymer content (in other words, the decrease in QD density, Table 1 and Figure 3c), indicating that the efficient suppression of electron injection from $\mathrm{ZnO}$ into QDs is provided by the polymer incorporation. The decrease in the current density due to the incorporation of polymer brushes has also been observed in the $J-V$ characteristics of electron-only devices (EODs) (Figure S13, Supporting Information) with QD-only and QD-BP1 hybrid active layers. In the EODs, the current measured originates solely from the electrons passing through the device, thus the detected decrease in the current densities clearly verifies the electron blocking abilities of the polymer BP1 as the result of its high LUMO level. Additionally, due to the hole conducting ability and the relatively low HOMO of the BP1 polymer, the polymer brushes, attached to QD surfaces, also facilitate the efficient hole transport within the hybrid emission layers. ${ }^{[24,25]}$ In other words, the functionalization of QDs with semiconducting polymer brushes (BP1) helps to improve the charge balance within QDs, thus reducing the chances for non-radiative Auger recombination process and ultimately leading to the enhancement of device efficiency (Table 2). The optimal QD density and thus the optimal charge balance are found with the hybrid $\mathrm{H} 2$ which results in the device with the best characteristics.
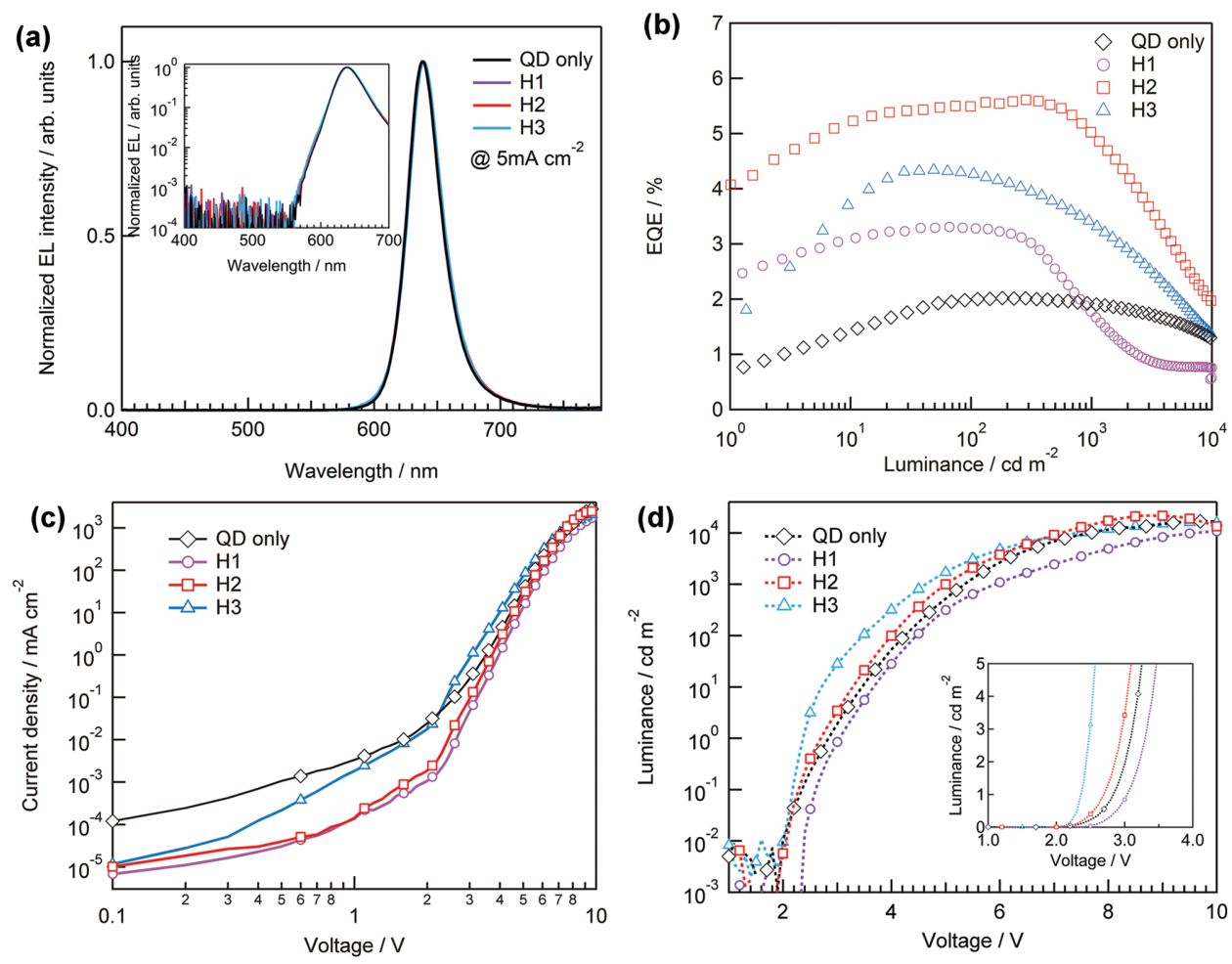

Figure 3. Device characteristic of hybrid $\mathrm{H} 1-\mathrm{H} 3$ and QD-only QLEDs: a) Normalized electroluminescence intensity (inset: normalized EL intensity shown in the log scale), b) EQE versus luminance, c) current density versus voltage, and d) luminance versus voltage (inset: magnified graph near the turn-on voltage). 


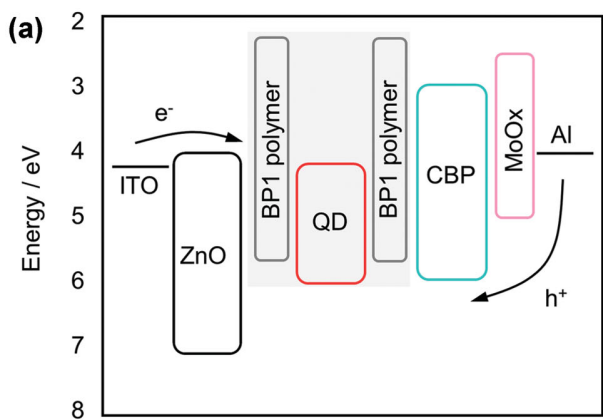

(c)

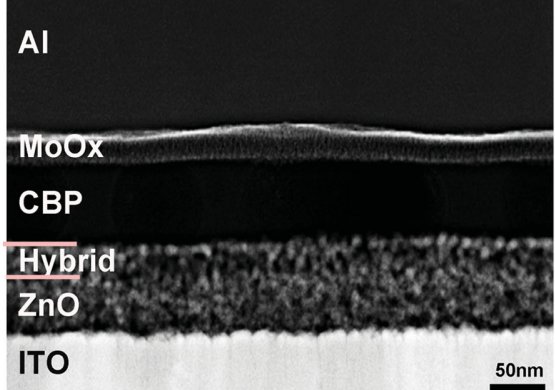

(e)

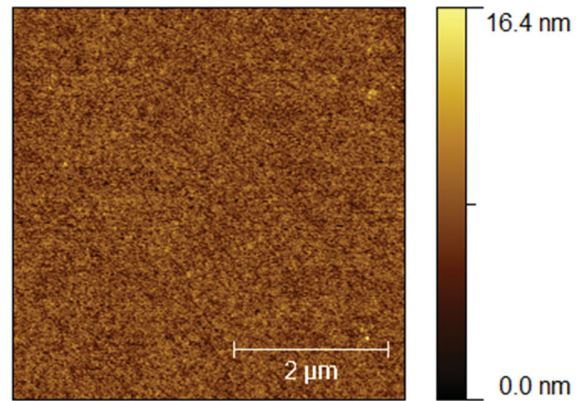

(b) 2

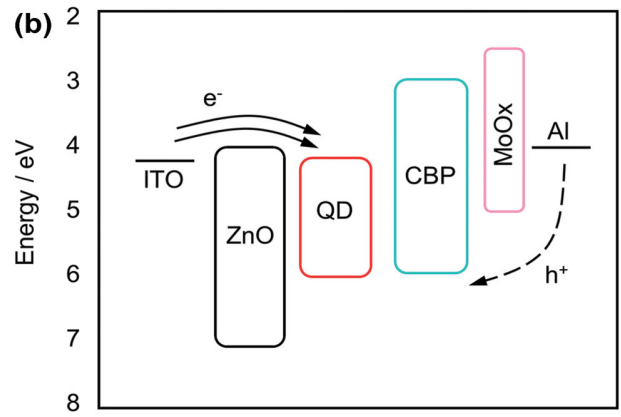

(d)

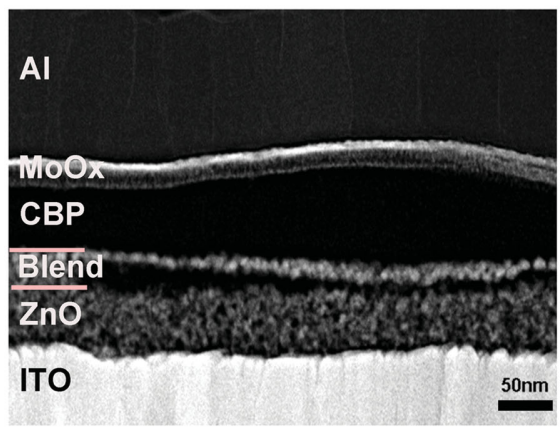

(f)

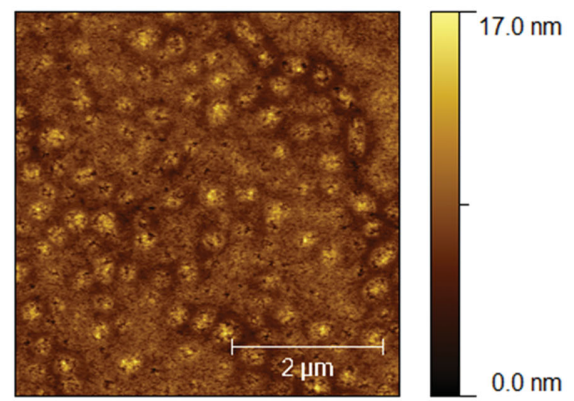

Figure 4. Energy diagram of a) hybrid QLED and b) QD-only QLED. The cross-section STEM images (dark field) of c) hybrid QLED (H2) and d) blend QLED (B2) (scale bar $50 \mathrm{~nm}$ ). AFM height images of e) hybrid QLED and f) blend QLED (scale bar $2 \mu \mathrm{m}$ ).

The disparity in the characteristics of hybrid and blend devices originates from the differences in the morphology of the emission layers. In the hybrid emission layer, QDs are rather homogeneously distributed within the polymer BP1 (Figure 4c,e). As can be seen in the cross-section STEM image of the QLED with a hybrid $\mathrm{H} 2$ emission layer, QDs (bright spots), and polymers (dark area) are uniformly intermixed throughout the entire film thickness as well as length of the emission layer. Such morphology facilitates the formation of semiconducting polymer shells around individual QDs, thus ensuring the polymer participation in the charge balance adjustment in QDs. In contrast to the hybrid emission layer, the physically blended QD/polymer film shows a massive phase separation between polymer (P1') and QDs in both lateral (Figure 4f) and vertical (Figure 4d) directions. Polymer P1' (dark) forms a separate interlayer, adjacent to the $\mathrm{ZnO}$ electron transport layer, while thin QD layer (bright) is sandwiched between polymer $\mathbf{P} \mathbf{1}^{\prime}$ and the CBP hole transport layer. The presence of polymer interlayer between QDs and ZnO still impedes the electron injection and helps to reduce the leakage current for the blend QLED (Figure 2c). However, the inhomogeneity in the morphology of the QD/polymer blend film does not guarantee the uniform charge transfer/injection into the emission layer and thereby the improved charge balance is not achieved. We attribute the inhomogeneity of the blend emission layer as the reason for the low device efficiency of the blend QLEDs when compared to the hybrid QLEDs.

ET process among QDs in the emissive layer and subsequence PL quenching has been known to be responsible for the reduction in the device efficiency. ${ }^{[10,30,31]}$ Assuming that the radiative exciton recombination rate $\left(\tau_{\mathrm{r}}\right)$ does not alter throughout the film formation, the ratio between PL decay lifetime obtained from the film $\left(\tau_{1 / \mathrm{e}}\right)$ and the radiative exciton recombination rate $\left(\tau_{\mathrm{r}}\right)$ approximates the PL QY of the film. ${ }^{[10]}$ The radiative exciton recombination rates measured with QDs in solution containing pristine QDs, QD-BP1 hybrids, or QD/ P1 blends are all similar with the PL lifetimes of $\approx 25.0 \mathrm{~ns}$ (Figure 1c), indicating that the exciton decay dynamics are preserved throughout the hybridization and blending processes. However, the PL decay dynamics of the emission layers within devices show substantial differences (Figure 5a): the QD PL lifetime in the device with a hybrid $\mathrm{H} 2$ emission layer was estimated to be $12.1 \mathrm{~ns}$, while the devices with the blend $\mathbf{B} 2$ and the QD-only emission layers show lifetimes of 8.8 and $8.4 \mathrm{~ns}$, 

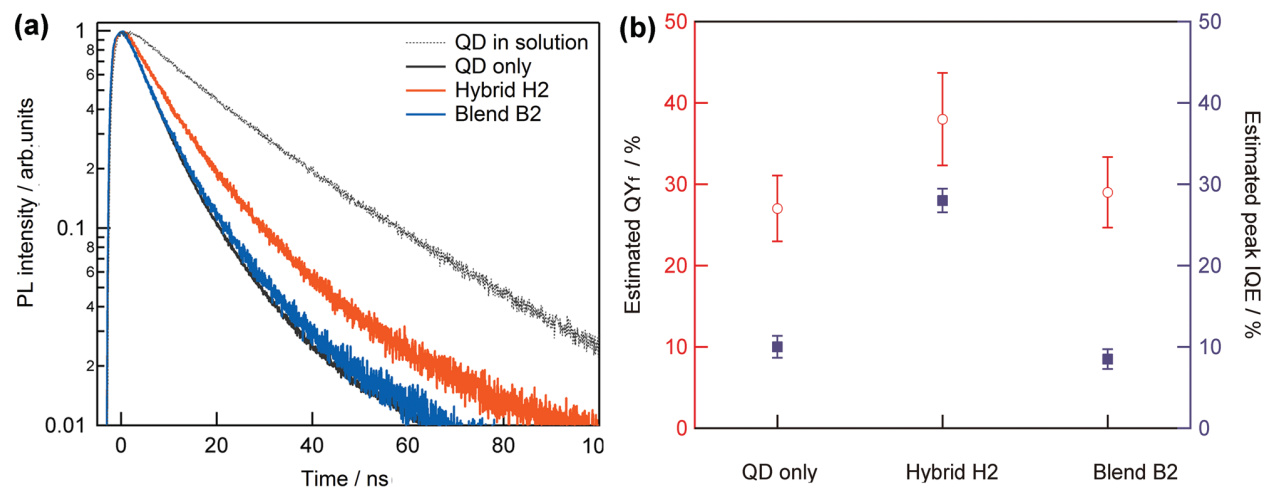

Figure 5. a) PL decay dynamics of a QD-BP1 hybrid film (hybrid $\mathrm{H} 2$ ), a $\mathrm{QD} / \mathrm{P} \mathrm{P}^{\prime}$ blend film (blend $\mathrm{B} 2$ ), and a $\mathrm{QD}$-only film in actual QLEDs. The PL decay dynamics of QD solution is also shown for comparison. b) Estimated internal quantum efficiency versus PL QYs of QD-BP1 hybrid film (hybrid $\mathrm{H} 2$ ), QD-only film, and QD/P1' blend film (blend B2).

respectively. Such a significant drop in the PL lifetime compared to the solution sample is a consequence of ET among QDs within the films.

Excitons are subject to undergo the non-radiative recombination during repeated ET processes, leading to the reduction in QYs of the emission layers. In the case of QD-only or blend emission layers in which QDs are packed closely together with short core-to-core distances $(\approx 10.1 \mathrm{~nm}$, Table 2$)$, the exciton more efficiently migrates among neighboring QDs via FRET (Förster resonance energy transfer) compared to the case of the hybrid emission layer, in which QDs are uniformly separated by the hybridized polymer brushes. ${ }^{[10]}$ The increase in the mean inter-QD distance with the hybrid emission layers suppresses the ET process in the films, thereby helping to preserve the QY of the emission layer. In the blend device, the loss in the PL lifetime remains comparable to the QD-only case due to the massive phase separation between QDs and polymers, which prevents the increment of QD-to-QD distance (Figure 4d).

Figure $5 \mathrm{~b}$ compares the estimated PL QY of emission layers $\left(Q_{f}\right)$ and the peak internal quantum efficiencies (IQEs) of the devices. $\mathrm{QY}_{\mathrm{f}}$ was calculated from the ratio between the PL decay lifetime obtained from the film $\left(\tau_{1 / \mathrm{e}}\right)$ and the radiative exciton recombination rate $\left(\tau_{\mathrm{r}}\right)$ (Equation $(1)$ ) and the peak IQE was estimated from the peak EQE (Equation (2))

$Q Y_{\mathrm{f}}=\tau_{1 / \mathrm{e}} / \tau_{\mathrm{r}} \times \mathrm{QY}_{\text {solution }}$, where $\mathrm{QY} \mathrm{Y}_{\text {solution }}=80 \%$

$\mathrm{IQE}=\mathrm{EQE} / \eta_{\text {ext }}$, where $\eta_{\text {ext }}$ denotes the extraction efficiency

$$
\times(=0.2)
$$

QYs diminish when casted in films as a result of ET process and subsequent QD quenching, and further decrease in an operating device due to charge carrier imbalance and Auger recombination. The hybridization imposes beneficial effects on QY of the emission layers in both steps. The polymer brushes in the QD-BP1 hybrids increase the mean inter-QD distance and thereby suppress the ET process, which is represented by the higher $\mathrm{QY}_{\mathrm{f}}$ value for the hybrid film compared to the QD-only and blended films. In addition, the semiconducting polymer brushes improve the charge balance within QDs by impeding the electron injection rates and, at the same time, facilitating the hole injection rate, which further contributes to significant enhancement of IQE of the hybrid films. Overall, the hybrid emission layer shows higher QY under the device operation conditions, enabling to achieve the high-efficiency QLEDs.

\section{Conclusion}

In this study, we presented the systematic analysis on the relationship between the morphology of emission layers and the device performance based on the QD-semiconducting polymer hybrid systems. The hybrid systems where semiconducting polymers are chemically grafted onto the QD surfaces lead to the uniform distribution of QDs within polymer matrices throughout the entire emission layer. We show that the functionalization of QDs with carbazole-based polymer brushes leads, on one hand, to the improved charge transport balance. This results from the combination of a high LUMO level (hindered electron transport into QDs and the prevention electron overcharge) with a relatively low HOMO level (efficient injection of holes into QDs) of the polymer used. On the other hand, the polymer brushes separate individual QDs and thus suppress PL quenching. As a result, we can fabricate a color-saturated red $\left(\lambda_{\max }=639 \mathrm{~nm}\right.$ with a full width at half maximum (FWHM) of $33 \mathrm{~nm}$ ) QLED with the peak efficiency of 5.6\%, which is over twofold higher than that of the devices based on QD-only and physically blended polymer/QD emission layers. A great attention should be paid to the morphologies of such systems as they have an enormous influence on the device characteristics and improvement opportunities. We believe that this systematic study opens up new opportunities for the applications of various combinations of QDs, semiconducting polymers, and device architectures on top of enabling further developments of hybrid QLEDs and other optoelectronic devices.

\section{Experimental Section}

Synthesis of $C d S e / C d_{x} Z n_{1-x} S$ QDs: QD synthesis was performed under inert conditions using Schlenk line technique. $0.5 \mathrm{~m}$ cadmium oleate $\left[\mathrm{Cd}(\mathrm{OA})_{2}\right]$ in 1-octadecene (ODE), $0.5 \mathrm{~m}$ zinc oleate $\left[\mathrm{Zn}(\mathrm{OA})_{2}\right]$ in $\mathrm{ODE}$, $2.0 \mathrm{~m}$ selenium in triotylphosphine (TOPSe), and $2 \mathrm{~m}$ sulfur in TOP 
(TOPS) stock precursor solutions were prepared and subsequently degassed under vacuum for $1 \mathrm{~h}$, and stored under $\mathrm{N}_{2}$ atmosphere. CdO (1 mmol), myristic acid (MA) (3 mmol), and ODE (15 mL) were loaded into a three-neck flask and heated up to $300{ }^{\circ} \mathrm{C}$ under inert conditions to form a clear solution of $\mathrm{Cd}(\mathrm{MA})_{2}$. Subsequently, the solution of $2 \mathrm{M}$ TOPSe $(0.25 \mathrm{~mL})$ was rapidly injected into the reaction flask to nucleate $\mathrm{CdSe}$ cores. After $3 \mathrm{~min}$ of reaction $0.5 \mathrm{M} \mathrm{Zn}(\mathrm{OA})_{2}(3 \mathrm{~mL})$ precursor and 1-dodecanethiol (DDT) (1 mmol) were added dropwise over $\approx 1 \mathrm{~min}$. The reaction was continued for 30 min to grow the inner $Z_{0.4} \mathrm{Cd}_{0.6} \mathrm{~S}$ shell. Subsequently, $0.5 \mathrm{M} \mathrm{Cd}(\mathrm{OA})_{2}(2 \mathrm{~mL}), 0.5 \mathrm{M} \mathrm{Zn}(\mathrm{OA})_{2}(4 \mathrm{~mL})$, and $2 \mathrm{~m}$ TOPS $(1.5 \mathrm{~mL})$ were added to the reaction flask for $\mathrm{Zn}_{0.5} \mathrm{Cd}_{0.5} \mathrm{~S}$ shell growth. Synthesized QDs were purified five times by the precipitation/ redispersion (ethanol/toluene) method.

Synthesis of Semiconducting Homopolymer P1: Monomer M1 $(1.0 \mathrm{~g}, 3.53 \mathrm{mmol}),{ }^{[25]}$ chain transfer agent, 2-cyano-2-propyl dodecyl trithiocarbonate $(13.55 \mathrm{mg}, 0.039 \mathrm{mmol})$, and initiator 2,2'-azobis (2methylpropionitrile) (AIBN) (1.08 mg, $0.0065 \mathrm{mmol}$ ) were dissolved in dry THF (15 mL) and degassed via three freeze-pump-thaw cycles. At the end the flask was filled with nitrogen and sealed. Afterward, the polymerization solution was immerged into preheated oil bath and left to react at $65^{\circ} \mathrm{C}$ for $48 \mathrm{~h}$. Subsequently, the reaction solution was rapidly cooled down by immersing the flask into liquid nitrogen for several seconds. The formed polymer and excess monomer were first precipitated into hexanes. For purification the polymer was repeatedly redissolved in THF and precipitates into suitable solvent. The remaining solutions containing excess of the monomer were collected and the unreacted monomer recovered for use in future reactions. The collected polymer was dried at $30{ }^{\circ} \mathrm{C}$ in vacuum for $24 \mathrm{~h} . M_{\mathrm{n}}=5900 \mathrm{~g} \mathrm{~mol}^{-1}$, PDI 1.2. ' $\mathrm{H}$ NMR (400 MHz, $\left.\mathrm{CDCl}_{3}, \delta\right): 8.13-7.88$ (br, $2 n \mathrm{H}$, carbazole), 7.38-6.81 (br, $6 n \mathrm{H}$, carbazole), 6.59-6.26 (br, $2 n \mathrm{H}$, benzyl), 6.26-5.73 (br, $2 n \mathrm{H}$, benzyl), 5.30-4.67 (br, $2 n \mathrm{H}$, benzyl- $\left.\mathrm{CH}_{2}\right), 1.77-1.33(\mathrm{~m}, 1 n \mathrm{H}$, backbone), 1.19-0.65 (br, $2 n \mathrm{H}$, backbone), $n$ : number of repeat units of P1 determined by GPC.

Synthesis of the Block Copolymer bP1: Homopolymer P1 (250 mg, $0.045 \mathrm{mmol})$, pentafluorophenyl acrylate (PFPA) $(865.85 \mathrm{mg}$, $0.020 \mathrm{mmol})$, and AIBN $(0.93 \mathrm{mg}, 0.0057 \mathrm{mmol}$ ) were dissolved in dry THF $(3.5 \mathrm{~mL})$ and degassed via three freeze-pump-thaw cycles. At the end the flask was filled with nitrogen and sealed. Afterward, the polymerization solution was immerged into preheated oil bath and left to react at $65^{\circ} \mathrm{C}$ for $69 \mathrm{~h}$. Subsequently, the reaction solution was rapidly cooled down by immersing the flask into liquid nitrogen for several seconds. The formed polymer and excess monomer were first precipitated into hexanes. For purification the polymer was repeatedly redissolved in THF and precipitates into hexanes. The remaining solutions containing excess of the monomer were collected and the unreacted monomer recovered for the use in future reactions. The collected polymer was dried at $30^{\circ} \mathrm{C}$ in vacuum for $24 \mathrm{~h}$. $M_{\mathrm{n}}=6300 \mathrm{~g} \mathrm{~mol}^{-1}$, PDI 1.2. ${ }^{1} \mathrm{H}$ NMR $\left(400 \mathrm{MHz} \mathrm{CDCl}_{3}, \delta\right): 8.13-7.88$ (br, $2 n \mathrm{H}$, carbazole), 7.38-6.81 (br, $6 n \mathrm{H}$, carbazole), 6.59-6.26 (br, $2 n \mathrm{H}$, benzyl), 6.26-5.73 (br, $2 n \mathrm{H}$, benzyl), 5.30-4.67 (br, $2 n \mathrm{H}$, benzyl $\left.-\mathrm{CH}_{2}\right)$, 5.30-4.67 $(\mathrm{m}, 0.25 \mathrm{nH}$, PFPA backbone), 5.30-4.67 $(\mathrm{m}, 0.55 \mathrm{nH}$, PFPA backbone), 1.77-1.33 (m, $1 n \mathrm{H}$, backbone), 1.19-0.65 (br, $2 n \mathrm{H}$, backbone), $n$ : number of repeat units of $\mathrm{Pl}$ determined by $\mathrm{GPC} .{ }^{19} \mathrm{~F}$ NMR $\left(282 \mathrm{MHz}, \mathrm{CDCl}_{3}, \delta\right):-155(2 \mathrm{H}),-159(1 \mathrm{H}),-1643(2 \mathrm{H})$.

Synthesis of the Block Copolymer BP1: The polymer bP1 and 70 eq. of AIBN were dissolved in dry THF and stirred at $75^{\circ} \mathrm{C}$ for $24 \mathrm{~h}$ to remove the trithiocarbonate group of CTA. The reaction solution was cooled down and repeatedly precipitated into hexanes/diethyl ether $3 / 1$. The obtained polymer was dried at $30^{\circ} \mathrm{C}$ in vacuum for $24 \mathrm{~h}$. Subsequently, the polymer was subjected to the post-polymerization modification reaction to introduce disulfide anchor groups. End group modified bP1 (200 mg, $0.036 \mathrm{mmol}$ ), 2-methyldithio-ethylamine (448 mg, $3.64 \mathrm{mmol})$, and triethylamine $(1 \mathrm{~mL}, 7.27 \mathrm{mmol})$ were dissolved in dry THF $(3 \mathrm{~mL})$ and stirred for $24 \mathrm{~h}$ at $30{ }^{\circ} \mathrm{C}$. The reaction solution was repeatedly precipitated into methanol and hexanes. The polymer (190 mg, $0.033 \mathrm{mmol}$ ) was obtained as colorless powder and dried at $30{ }^{\circ} \mathrm{C}$ in vacuum for $24 \mathrm{~h}$. The successful modification was verified via ${ }^{19} \mathrm{~F}$ spectroscopy (no signals). $M_{\mathrm{n}}=6200 \mathrm{~g} \mathrm{~mol}^{-1}$, PDI 1.2. ${ }^{1} \mathrm{H} \mathrm{NMR}$
(400 MHz, $\left.\mathrm{CDCl}_{3}, \delta\right): 8.13-7.88(\mathrm{br}, 2 n \mathrm{H}$, carbazole), 7.38-6.81 (br, $6 n \mathrm{H}$, carbazole), 6.59-6.26 (br, $2 n \mathrm{H}$, benzyl), 6.26-5.73 (br, $2 n \mathrm{H}$, benzyl), 5.30-4.67 (br, $2 n \mathrm{H}$, benzyl $\left.-\mathrm{CH}_{2}\right), 3.80-3.34\left(\mathrm{~m}, 0.44 n \mathrm{H},-\mathrm{CH}_{2}-\mathrm{CH}_{2}-\right.$ $\left.\mathrm{S}-\mathrm{S}-\mathrm{CH}_{3}\right), 3.01-2.65\left(\mathrm{~m}, 0.46 n \mathrm{H},-\mathrm{CH}_{2}-\mathrm{CH}_{2}-\mathrm{S}-\mathrm{S}-\mathrm{CH}_{3}\right), 2.50-2.01$ $\left(\mathrm{m}, \quad 1.05 \mathrm{nH}, \quad-\mathrm{CH}_{2}-\mathrm{CH}_{2}-\mathrm{S}-\mathrm{S}-\mathrm{CH}_{3}\right.$, amide backbone), 1.77-1.33 ( $\mathrm{m}, 1.5 \mathrm{nH}$, backbone, amide backbone), 1.19-0.65 (br, $2 n \mathrm{H}$, backbone), $n$ : number of repeat units of P1 determined by GPC.

General Procedure for the Synthesis of QD/Polymer Hybrids $(\mathrm{H} 1-\mathrm{H} 3)$ and Blends (B1-B3): For the synthesis of hybrids block copolymer BP1 was used and for the synthesis of blends the homopolymer $\mathrm{PI}^{\prime}$ without anchor groups was used. Polymer $(8.9,6.7$, or $4.4 \mathrm{mg}$ depending on the sample) and QDs (red, CdSe core, core diameter $4 \mathrm{~nm}, \mathrm{Cd}_{x} \mathrm{Zn}_{1-x} \mathrm{~S}$ shell, total diameter $9 \mathrm{~nm}$, oleic acid ligands, $17.7 \mathrm{mg}$ ) were separately dissolved in chlorobenzene (each $100 \mu \mathrm{L}$ ) and subsequently combined. The reaction mixture was sonicated for $1 \mathrm{~h}$ and ethanol $(1.5 \mathrm{~mL})$ was added. The formed sediment was dispersed in chlorobenzene $(250 \mu \mathrm{L})$, sonicated for one additional hour and left at room temperature for $18 \mathrm{~h}$. Afterward, ethanol $(1.5 \mathrm{~mL})$ was added and the formed sediment was again dispersed in chlorobenzene and sonicated for $1 \mathrm{~h}$. After addition of ethanol the sediment was dried and dispersed in the appropriate amount of toluene to obtain $\mathrm{QD} /$ polymer hybrid solution with the total concentration of $19.8 \mathrm{mg} \mathrm{mL}^{-1}$.

Device Fabrication and Characterization: The patterned ITO glass substrates were cleaned using acetone, isopropanol, deionized water in an ultrasonic bath. The dispersion of $\mathrm{ZnO}$ nanoparticle in butanol was spun onto the substrate with $2000 \mathrm{rpm}$ for $40 \mathrm{~s}$ and substrate was dried under $\mathrm{N}_{2}$ at $100{ }^{\circ} \mathrm{C}$ for $30 \mathrm{~min}$. Active layers were similarly cast from polymer/QD hybrid solution which was dissolved in toluene, and followed by drying in $\mathrm{N}_{2}$ oven at $100{ }^{\circ} \mathrm{C}$ for $5 \mathrm{~min}$. The $\mathrm{CBP}, \mathrm{MoO}_{3}$, and $\mathrm{Al}$ were successively deposited on top of each active layer. The vacuum deposition was done under high vacuum $\left(3-5 \times 10^{-6}\right.$ torr) with deposition rate of $0.5-1 \AA \mathrm{s}^{-1}$ for $\mathrm{CBP}, 0.2 \AA \mathrm{s}^{-1}$ for $\mathrm{MoO} 3$, and $4-5 \AA \mathrm{s}^{-1}$ for Al layer. The current-voltage-luminance $(I-V-L)$ characteristics of the devices were obtained by a Keithley-236 source-measure unit, a Keithley-2000 multimeter, and a calibrated Si photodiode (Hamamatsu S5227-1010BQ). The EL spectra of the device were measured by using Konica-Minolta spectroradiometer (CS-1000A).

\section{Supporting Information}

Supporting Information is available from the Wiley Online Library or from the author.

\section{Acknowledgements}

A.F. and Y.L. contributed equally to this work. This work was supported by the International Research Training Group (IRTG 1404) Program (Grant No. 2014001836 funded by NRF and DFG). A.F. acknowledges the financial support from graduate school MAINZ and is a recipient of the fellowship through the Excellence Initiative (DFG/CSC 266). Y.L. acknowledges the financial support from the Industrial Strategic Technology Development Program (10045145) funded by MOTIE, Korea and was also supported by the Human Resources Development program (No. 20124010203170) of the KETEP grant funded by the Korea government Ministry of Trade, Industry, and Energy. K.C. acknowledges the financial support from NRF of Korean for the National Creative Research Initiative Program (Grant No. 2010-001829) and the Gutenberg Research College fellowship. W.K.B. acknowledges Korea Institute of Science and Technology (KIST, 2E25393) and Korea Evaluation Institute of Industrial Technology (KEIT, 2MR3600).

Received: April 2, 2016

Revised: June 6, 2016

Published online: July 11, 2016 
[1] X. Dai, Z. Zhang, Y. Jin, Y. Niu, H. Cao, X. Liang, L. Chen, J. Wang, X. Peng, Nature 2014, 515, 96.

[2] Y. Yang, Y. Zheng, W. Cao, A. Titov, J. Hyvonen, J. R. Manders, J. Xue, P. H. Holloway, L. Qian, Nat. Photonics 2015, 9, 259.

[3] B. S. Mashford, M. Stevenson, Z. Popovic, C. Hamilton, Z. Zhou, C. Breen, J. Steckel, V. Bulovic, M. Bawendi, S. Coe-Sullivan, P. T. Kazlas, Nat. Photonics 2013, 7, 407.

[4] D. V. Talapin, I. Mekis, S. Götzinger, A. Kornowski, O. Benson, H. Weller, J. Phys. Chem. B 2004, 108, 18826.

[5] Y. Shirasaki, G. J. Supran, W. A. Tisdale, V. Bulović, Phys. Rev. Lett. 2013, 110, 217403.

[6] H. H. Kim, S. Park, Y. Yi, D. I. Son, C. Park, D. K. Hwang, W. K. Choi, Sci. Rep. 2015, 5, 8968.

[7] X. Yang, P. L. Hernandez-Martinez, C. Dang, E. Mutlugun, K. Zhang, H. V. Demir, X. W. Sun, Adv. Opt. Mater. 2015, 3, 1439.

[8] H. Shen, W. Cao, N. T. Shewmon, C. Yang, L. S. Li, J. Xue, Nano Lett. 2015, 15, 1211.

[9] J. Kwak, W. K. Bae, D. Lee, I. Park, J. Lim, M. Park, H. Cho, H. Woo, D. Y. Yoon, K. Char, S. Lee, C. Lee, Nano Lett. 2012, 12, 2362.

[10] J. Lim, B. G. Jeong, M. Park, J. K. Kim, J. M. Pietryga, Y.-S. Park, V. I. Klimov, C. Lee, D. C. Lee, W. K. Bae, Adv. Mater. 2014, 26, 8034.

[11] W. K. Bae, Y.-S. Park, J. Lim, D. Lee, L. a. Padilha, H. McDaniel, I. Robel, C. Lee, J. M. Pietryga, V. I. Klimov, Nat. Commun. 2013, 4, 2661.

[12] K.-S. Cho, E. K. Lee, W.-J. Joo, E. Jang, T.-H. Kim, S. J. Lee, S.-J. Kwon, J. Y. Han, B.-K. Kim, B. L. Choi, J. M. Kim, Nat. Photonics 2009, 3, 341.

[13] K. S. Leck, Y. Divayana, D. Zhao, X. Yang, A. P. Abiyasa, E. Mutlugun, Y. Gao, S. Liu, S. T. Tan, X. W. Sun, H. V. Demir, ACS Appl. Mater. Interfaces 2013, 5, 6535.

[14] B. N. Pal, Y. Ghosh, S. Brovelli, R. Laocharoensuk, V. I. Klimov, J. A. Hollingsworth, H. Htoon, Nano Lett. 2012, 12, 331.

[15] H. Shen, Q. Lin, H. Wang, L. Qian, Y. Yang, A. Titov, J. Hyvonen, Y. Zheng, L. S. Li, ACS Appl. Mater. Interfaces 2013, 5, 12011.
[16] J. Tao, H. Wang, Q. Lin, H. Shen, L. S. Li, IEEE Trans. Nanotechnol. 2015, 14, 57.

[17] W.-K. Koh, T. Shin, C. Jung, K.-S. Cho, ChemPhysChem 2016, DOI: 10.1002/cphc. 201600054.

[18] Y. Li, A. Rizzo, M. Mazzeo, L. Carbone, L. Manna, R. Cingolani, G. Gigli, J. Appl. Phys. 2005, 97, 113501.

[19] K. Kwak, K. Cho, S. Kim, Appl. Phys. Lett. 2014, 104, 1.

[20] J. Zhou, W. Q. Tang, C. F. Wang, L. Chen, Q. Chen, S. Chen, J. Polym. Sci., Part A: Polym. Chem. 2012, 50, 3736.

[21] H. Jung, W. Chung, C. H. Lee, S. H. Kim, J. Nanosci. Nanotechnol. 2012, 12, 5407.

[22] F. Mathias, A. Fokina, K. Landfester, W. Tremel, F. Schmid, K. Char, R. Zentel, Macromol. Rapid Commun. 2015, 36, 959.

[23] J. Kwak, W. K. Bae, M. Zorn, H. Woo, H. Yoon, J. Lim, S. W. Kang, S. Weber, H.-J. Butt, R. Zentel, S. Lee, K. Char, C. Lee, Adv. Mater. 2009, 21, 5022.

[24] L. zur Borg, D. Lee, J. Lim, W. K. Bae, M. Park, S. Lee, C. Lee, K. Char, R. Zentel, J. Mater. Chem. C 2013, 1, 1722.

[25] A. Fokina, Y. Lee, J. H. Chang, L. Braun, W. K. Bae, K. Char, C. Lee, R. Zentel, Polym. Chem. 2016, 7, 101.

[26] J. Lim, B. G. Jeong, M. Park, J. K. Kim, J. M. Pietryga, Y.-S. Park, V. I. Klimov, C. Lee, D. C. Lee, W. K. Bae, Adv. Mater. 2014, 26, 8034.

[27] P. J. Roth, K.-S. Kim, S. H. Bae, B.-H. Sohn, P. Theato, R. Zentel, Macromol. Rapid Commun. 2009, 30, 1274.

[28] I. L. Medintz, H. T. Uyeda, E. R. Goldman, H. Mattoussi, Nat. Mater. 2005, 4, 435.

[29] Y.-S. Park, W. K. Bae, L. A. Padilha, J. M. Pietryga, V. I. Klimov, Nano Lett. 2014, 14, 396.

[30] C. Javaux, B. Mahler, B. Dubertret, A. Shabaev, A. V. Rodina, A. L. Efros, D. R. Yakovlev, F. Liu, M. Bayer, G. Camps, L. Biadala, S. Buil, X. Quelin, J.-P. Hermier, Nat. Nanotechnol. 2013, 8, 206.

[31] C. R. Kagan, C. B. Murray, M. Nirmal, M. G. Bawendi, Phys. Rev. Lett. 1996, 76, 1517. 